\title{
Optometry outreach for diverse middle school students
}

\section{Pamela Gilchrist, Alonzo Alexander}

Pamela O. Gilchrist, Alonzo B. Alexander, "Optometry outreach for diverse middle school students," Proc. SPIE 11143, Fifteenth Conference on Education and Training in Optics and Photonics: ETOP 2019, 111430L (2 July 2019); doi: 10.1117/12.2523998 


\title{
Optometry Outreach for Diverse Middle School Students
}

\author{
Pamela O. Gilchrist*a, Alonzo B. Alexander ${ }^{b}$
}

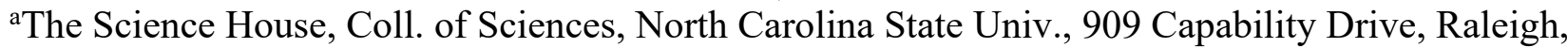
NC, USA 27606; ' Coll. of Education, North Carolina State Univ., 2310 Katharine Stinson Drive, Raleigh, NC USA 27695

\begin{abstract}
A need exists to diversify the optometry field in the United States. Males reflect 50.4 percent of the profession and approximately $97 \%$ of optometrist professionals are White and Asian ${ }^{1}$. This paper will describe Imhotep Academy's program model, implementation efforts, and preliminary findings of the "Imhotep Academy: Optics of the Eye" session designed to promote optics content, optometry careers, engagement with diverse professionals within the field, and optics hands-on experiences to ethnically and racially diverse middle school students. The paper will analyze students' awareness and knowledge of optics, science, technology, engineering, and mathematics (STEM) fields, their proficiencies, and innovations in the optometry field that impact personal health outcomes as well as parent data. Lastly, the paper will provide findings related to students' self-reported 21st-century learning skills, future STEM engagement in school, and career aspirations. Informal science outreach programs have been found to develop students' awareness and knowledge of STEM careers.
\end{abstract}

Keywords: STEM, outreach, informal education, optics

\section{INTRODUCTION}

The strength of the STEM talent pool in the U.S. is critical not only to the country's global economic competitiveness, but also to national security ${ }^{2}$. STEM degrees are desirable to a wide range of employers because they incorporate $21^{\text {st }}$ century skills such as critical thinking, problem solving and teamwork ${ }^{3}$. Developing these skills is critical because the problems that we face today such as climate change, food deserts and cyber awareness require a diverse and functional skill set that is embodied in STEM degrees ${ }^{4}$. Graduating more U.S. college students in STEM has practical importance nationally, as fewer Americans fill skilled scientific and technical careers, damaging American economic competitiveness and potentially harming national security ${ }^{5}$. STEM education emphasizes an integrative strategy of teaching instead of the traditional silo approach, and skills such as teamwork, effective communication and innovation can be fostered.

Not only do STEM degrees provide a comprehensive skill set, but they also advance social justice and equity. For example, the attainment of STEM degrees provides a chance at economic parity for students born into low-income and low SES families since individuals who have STEM degrees are reported to accrue one million dollars more over a lifetime compared to people with non-STEM degrees ${ }^{3,5}$. However even with the current U.S. emphasis on STEM, degree rates for African Americans and Latinos continue to lag behind those of White and Asian students ${ }^{6}$. For instance, only $24 \%$ of URMs complete a bachelor's degree in science and engineering within six years of initial enrollment compared to $40 \%$ of Whites and $50 \%$ of Asian students. The National Science Foundation ${ }^{7}$ reported that although African American undergraduates were just as likely as Whites to major in STEM areas, they were much less likely to earn a degree in those majors. The research shows that even when students enter the STEM pipeline, many of them do not stay due to reasons such as low confidence in math and science, past poor performance in STEM subjects, discouragement, and lack of role models and mentors, and a lack of informal STEM experiences ${ }^{8}$. The research seems to imply that underrepresentation of minorities (URMs) is not necessarily due to a lack of interest in science fields, but related to a lack of knowledge and exposure to the possibilities that STEM careers can offer. Because of this, it is important to address the issue of attracting African-American and Latino students to the STEM pipeline and determine ways to improve persistence.

*pogilchr@ncsu.edu; $\quad$ phone 19919 515-5570; $\quad$ fax 1 919 515-7545; $\quad$ sciencehouse.ncsu.edu 
Research suggests that STEM persistence in education declines as children progress through the STEM pipeline as students formulate their opinions about STEM careers during their middle and high school years, and potentially even earlier therefore, it makes sense to center STEM interventions during middle and high school years ${ }^{9}$. However, students must have opportunities to acquire STEM skills and knowledge beyond the classroom. The 95 Percent Solution, by John Falk and Lynn Dierking stated that average Americans spend less than 5\% of their lives in classrooms, and that most science is actually learned outside of school ${ }^{10}$. Falk and Dierking also state that elementary children perform better or just as well as other children internationally. However, results compared with American middle and high school children internationally are mediocre and thus is an area of concern.

Many studies have identified a number of issues that cause a disparity between the demand and supply of qualified STEM graduates and as a result impact on the shortage of STEM-skilled professionals $\mathrm{s}^{11}$. Several studies suggested that students' perception and lack of understanding of STEM fields and careers often leads many young people to be disconnected from STEM, feeling that it is not for them ${ }^{11}$. One misconception that has negatively impacted students' attitudes as well as their perception of STEM subjects and careers is that STEM careers are male-oriented ${ }^{12}$. As young people during adolescence start to form an identity, their personal view of STEM impacts on their future career choices ${ }^{13}$.

The Optical Society of America (OSA) has identified that the greatest areas for growth exist within underrepresented populations ${ }^{14}$. OSA estimates that $80 \%$ of the growth in optics professionals will come from groups like Latinos and African-Americans. Additionally, the earning potential of an optics career in an industry with more than $\$ 400$ billion in business year-to-year has the potential to address issues of equity and income equality in these underserved groups ${ }^{15}$. Unfortunately, only $5.1 \%$ of the students attending optometry school in 2016 were of Hispanic or Latino, Black, American Indian, or Pacific Islander descent ${ }^{2}$. However, this may directly connect to a lack of knowledge about optics careers ${ }^{14}$. It is our belief that promoting optics content, optometry careers, engagement with diverse professionals within the field, and optics hands-on experiences will increase the number of ethnically and racially diverse middle school students who express interest in optics careers.

Optics education has been pursued with varying levels of success in both formal and informal settings ${ }^{16,17,18}$. However, Imhotep Academy's unique approach to delivering STEM content across the STEM disciplines (science, technology, engineering, and mathematics) is a unique effort in informal optics education. Imhotep Academy is a year-round middle school enrichment program that introduces students to the world of STEM with an emphasis on reaching underserved and students historically underrepresented in STEM disciplines. Imhotep aims to increase students' awareness and enthusiasm for learning STEM, build students' confidence and identity in STEM, and inspire students to continue studying STEM throughout high school and college. At Imhotep Academy, each of the disciplines of STEM is addressed through the curriculum.

\section{BACKGROUND AND METHODS}

\subsection{Pre-Assessment}

Middle school student knowledge of optics is limited to basic information and is often misinformed, leading to alternate conceptions of visual systems that persist beyond their school-age years ${ }^{19}$. Because of this, a pre-assessment was given to middle school participants to gauge where their alternate conceptions might lie. The survey covered topics ranging physical descriptions of the eye and its respective parts, mathematical questions related to lenses and magnification, and questions about careers in optics.

Table 1. Sample Items from Optics Pre-Assessment.

\begin{tabular}{|l|l|}
\hline \multicolumn{1}{|c|}{ Section } & \multicolumn{1}{|c|}{ Items } \\
\hline The Eye & $\begin{array}{l}\text { Can you name the parts of the human eye? Using the descriptions } \\
\text { given, see if you can name the individual parts of an eye model by } \\
\text { dragging the name of each part to its description. }\end{array}$ \\
\hline
\end{tabular}




\begin{tabular}{|l|l|}
\hline $\begin{array}{l}\text { Mathematics of the } \\
\text { Eye }\end{array}$ & $\begin{array}{l}\text { A 4.00-cm tall light bulb is placed a distance of } 8.30 \mathrm{~cm} \text { from a double } \\
\text { convex lens having a focal length of } 15.2 \mathrm{~cm} \text {. Using the lens equation, } \\
\text { determine the image distance and the image magnification. }\end{array}$ \\
\hline Careers in Optics & $\begin{array}{l}\text { Which of the following professionals can perform eye surgery? } \\
\text { (ophthalmologist, optometrist, orthoptist, optician) }\end{array}$ \\
\hline
\end{tabular}

Evaluating the assessment results, only $24 \%$ of students in the program could correctly describe the function of the retina; $21 \%$ could identify the function of the aqueous and vitreous humor; and only $17 \%$ could locate and describe the cornea. Issues of understanding also persisted in the mathematical section, as only half of participants could accurately locate an image created by light from an object traveling through a biconvex lens. Fewer than $10 \%$ correctly used the lens equation when given the height of an object, its distance from a lens, and the focal length of the lens. There were also alternate conceptions in the career section. Two-thirds of participants thought LASIK should be "considered dangerous" as a vision correction option, while fewer than half of students could identify the job description of an ophthalmologist. Given these results, an optics-focused STEM outreach effort was seen as essential.

\subsection{The S-STEM Instrument}

While student achievement data can be an important measure of success, student attitudes toward STEM have a strongly correlated relationship to whether students choose to pursue STEM careers in college and after graduation ${ }^{20}$. To assess the impact of the program on STEM attitudes, the Student Attitudes Toward STEM (S-STEM) survey instrument was used. The S-STEM survey instrument is a previously validated too ${ }^{21}$ that collects data in several specific categories: (1) attitudes and outcome measures toward STEM, (2) attitudes toward 21st century learning skills, (3) current and future interest in STEM careers, and (4) demographic characteristics. Responses are evaluated on a 5-point, increasing Likert scale from Strongly Disagree to Strongly Agree. Students were given the S-STEM before the start of the program and at the end of the program to discern any potential changes in their STEM attitudes.

\subsection{Imhotep Academy}

Imhotep Academy is an outreach program at NC State University with the mission to engage students traditionally underserved in STEM (African-Americans, Latin@s, Native Americans, girls) to varying topics in STEM (e.g. chemistry, mathematics, marine, earth and atmospheric sciences, physics) through laboratory experiences, research projects, classroom instruction and field trips. Additionally, participants learn about potential careers in these fields by discussing the contributions of STEM professionals from underrepresented groups. One of Imhotep Academy's primary goals is to build student self-efficacy and self-esteem related to pursuing a STEM career in the future. Students rotate through three classes focused on science, mathematics, and engineering/technology. Students are asked to make sense of the world using real problems connected and modeled with everyday scenarios.

Imhotep Academy Photonics Pre-College Program model (3PM) address how to prepare underrepresented minority K-12 students for science, technology, engineering and mathematics (STEM) careers and to equip teachers and parents with resources to engage learners in these disciplines (Figure 1). The program model is grounded in six components 1) Student Recruitment and Retention; 2) STEM Content; 3) Parental Engagement; 4) STEM Professionals, 6) Leadership and Professional Development; and 6) Evaluation and Dissemination. The bidirectional model (see Figure 1) focus on strategies that place student learning and experiences in STEM as the central focus ${ }^{26,27}$. The program model is guided by four principles:

1) Immersion in traditional and nontraditional hands-on, problem-based investigation;

2) Engagement in a supportive, safe and challenging environment and support system;

3) Participation in leadership and professional development training and

4) Integration of professionals from academia, industry, and schools with parents and students in synergistic STEM activities, internships and mentoring relationships.

Each principle is operationalized through one or more of the program components. Immersion in these components enhance participants (i.e. students or teachers) awareness of STEM careers by providing opportunities to participate in authentic learning experiences that expand the awareness of optics, electronics, computer hardware, and software while building participants' $21^{\text {st }}$ century learning skills needed for the global workforce. 
Programs that promote underrepresented minority students and women participation in engineering and the sciences would benefit from an employment. with targeted recruitment and retention approaches in the K-12 and higher education ${ }^{31}$. Students benefit from exposure to physics and engineering learning environments rich in multidisciplinary rigor, and interconnectedness with their daily lives. Parent encouragement and involvement is the single largest predictor of students' educational aspiration and academic preparation preceding college $\mathrm{e}^{23,24,25}$. The engagement of STEM professionals in informal programs and access to research occurring in laboratories through field trips, mentoring, and internship experiences provide students authentic introductions to STEM research ${ }^{24}$. Leadership experiences for students that develop students $21^{\text {st }}$ century learning skills ${ }^{30}$. Teacher professional developments on optics, light, and computer hardware and software using inquiry-based approaches and experiences in STEM researchers in laboratories and industries may equip educators with capacities to guide students through STEM investigations and inquiry-based experiences ${ }^{28,29}$. Evaluation and dissemination of findings from this multidimensional model provides a basis for understanding the role of the program components and strategies employed to prepare diverse students for STEM careers and the global workforce.

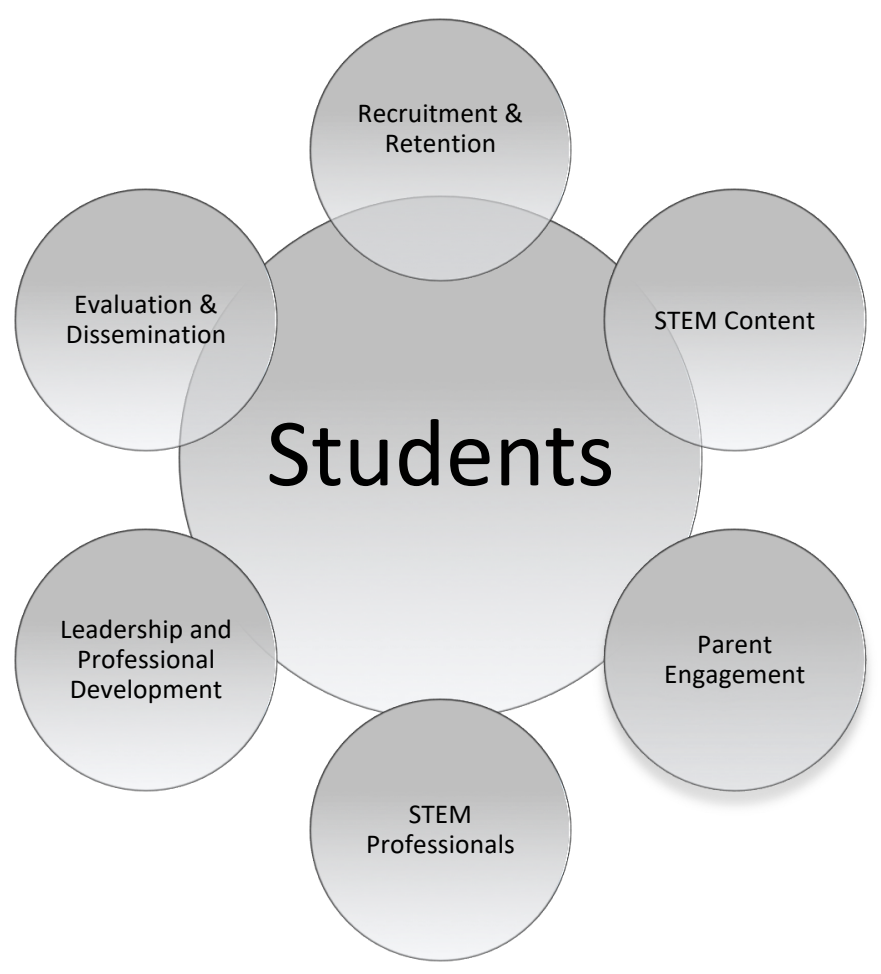

Figure 1. Imhotep Academy Photonics Pre-College Program (3PM) Model.

\section{OUTREACH INTERVENTION}

\subsection{A Program Lesson}

Imhotep Academy teaching staff and team develops integrated lesson plans and activities aligned with the Next Generation Science Standards (NGSS) and the North Carolina Standard Course of Study (NCES). While this lesson is described here, all the lessons offered at Imhotep Academy use a pedagogical approach of inquiry and problem-based learning, often with handouts for students. The 5E lesson planning tool is used to direct lesson planning, implementation and evaluation. For example, in the lessons shown below, students were guided through an exploration of how light rays refract, how lenses aid in the focusing of light, and how imperfections in the shape of an eye can cause myopia and hyperopia. Imhotep Academy lessons are designed to using common materials (e.g. resealable plastic bags, gelatin, compass) that can be found in local stores or in the average middle school classroom and extended by our access to researchers in the field. 


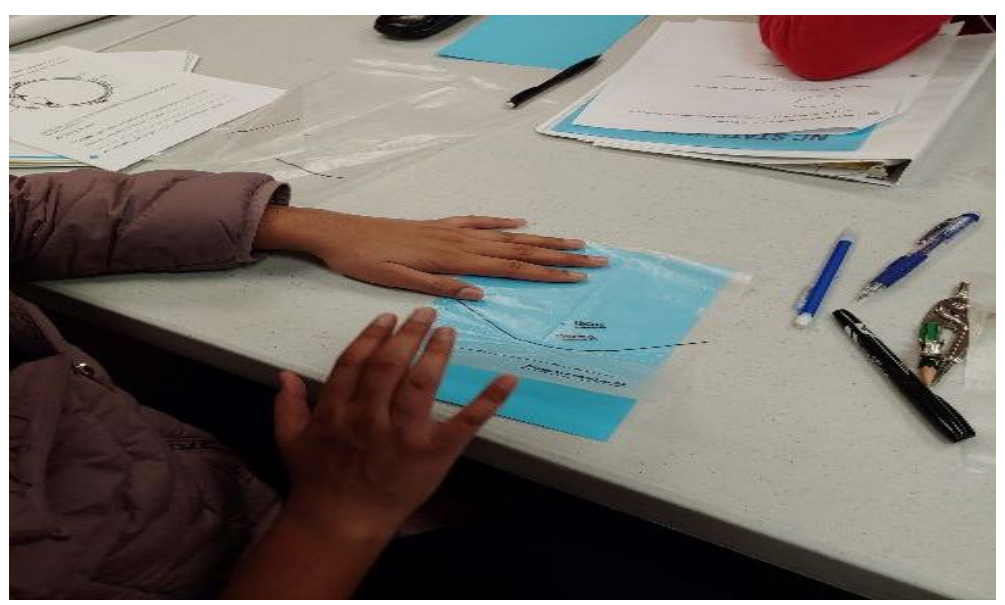

Figure 2. Students test their understanding of refraction and lenses by drawing a directrix.

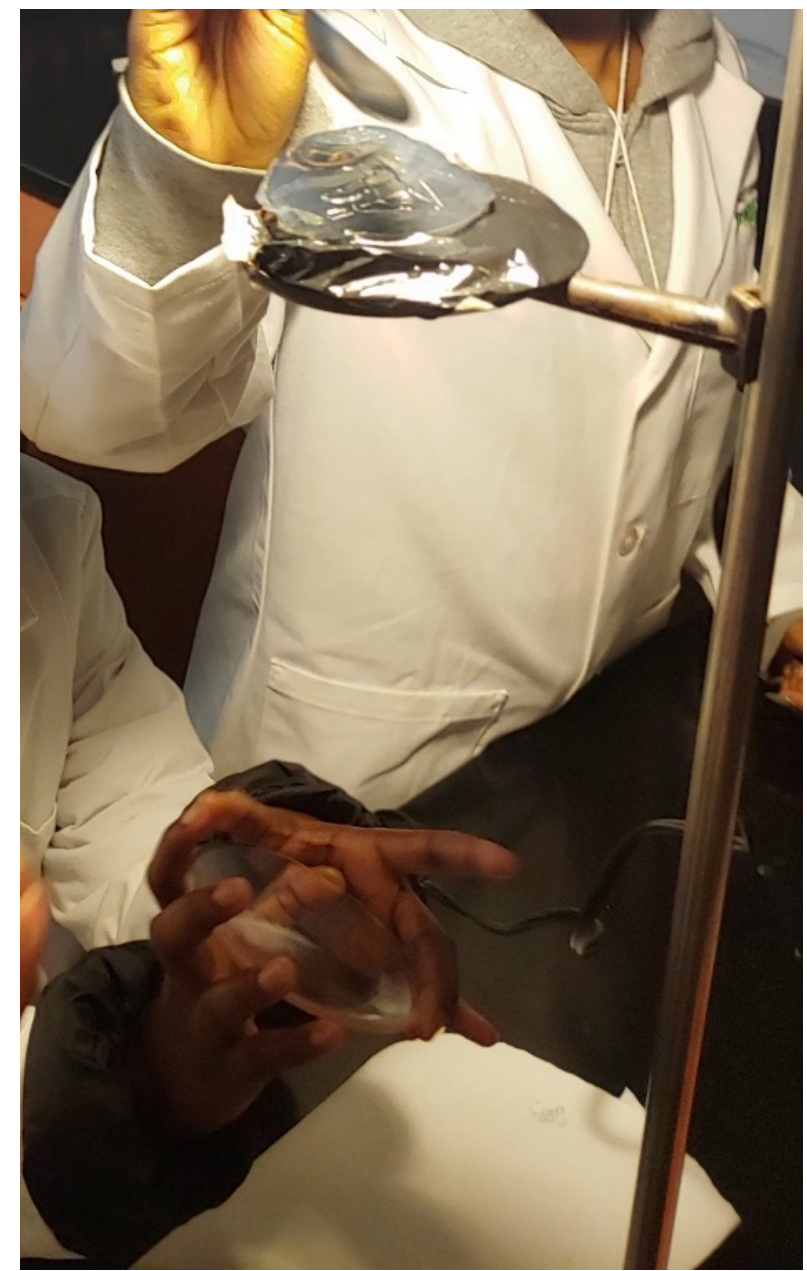

Figure 3. Students simulate changes to the lens with a model gelatin 'lens.'

Proc. of SPIE Vol. 11143 111430L-5

Downloaded From: https://www.spiedigitallibrary.org/conference-proceedings-of-spie on 26 Apr 2023 Terms of Use: https://www.spiedigitallibrary.org/terms-of-use 


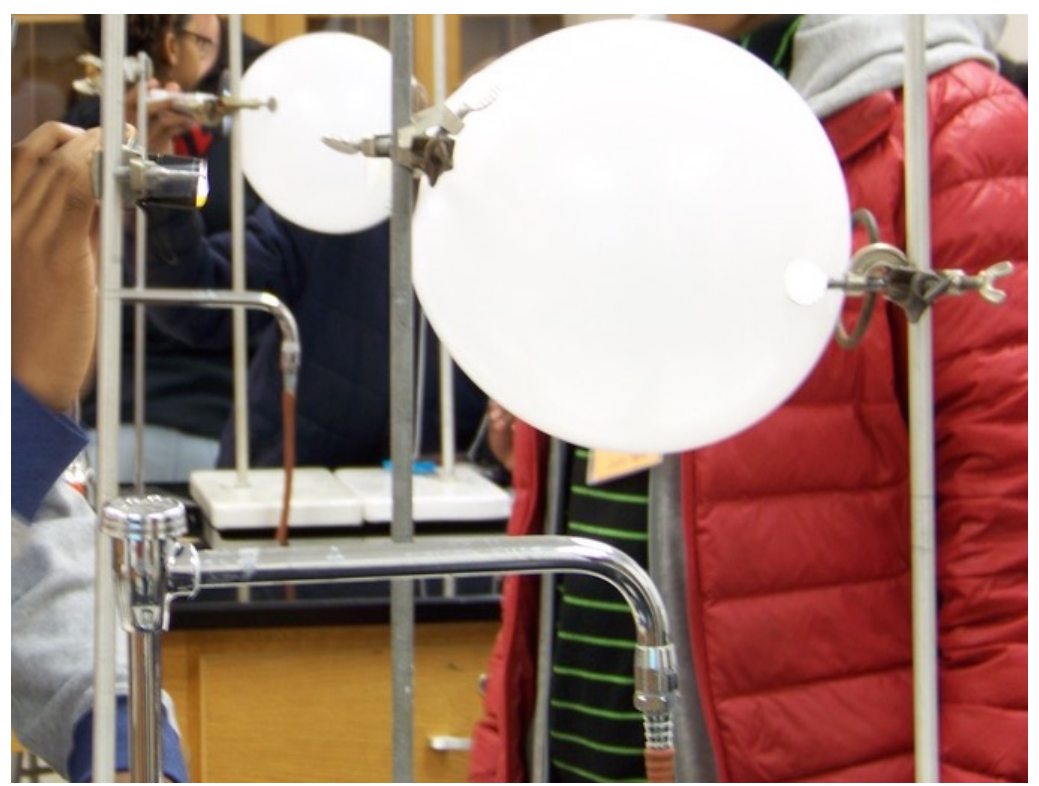

Figure 4. Students model nearsightedness and farsightedness using balloons and lenses.

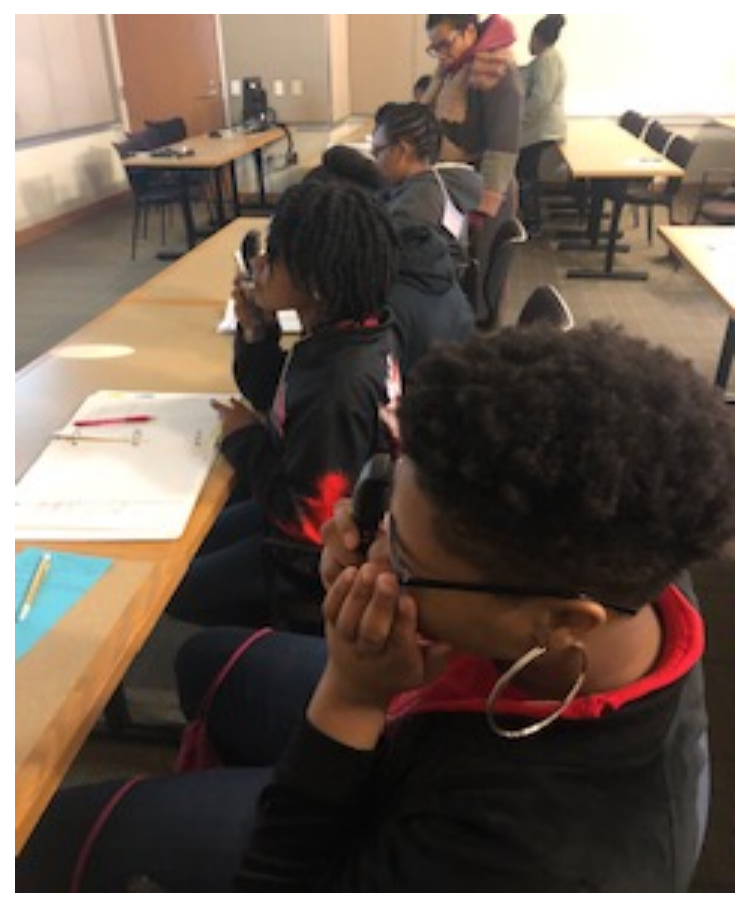

Figure 5. Students using a retinoscope during their Optics in Veterinary Ophthalmology tour at North Carolina State University School of Veterinary Medicine to view a myopic, hyperopic, and normal vision.

\section{RESULTS}

\subsection{Content Delivery}

The "Imhotep Academy: Optics of the Eye" session was designed to promote optics content, optometry careers, engagement with diverse professionals within the field, and optics hands-on experiences. The program was offered in five 4-hour sessions in the Spring of 2019 to a cohort of Imhotep Academy students $(\mathrm{N}=31)$. The majority of the sample was 
African-American $(n=26)$, while there was a near even split by sex (male=15; female=16). Middle school students comprised the cohort as shown in the table below.

Table 2. Sample by Grade Level.

\begin{tabular}{|llll|}
\hline Grade Level & Sex & Total \\
\hline & Male & Female & \\
6 & 6 & 7 & 13 \\
7 & 5 & 4 & 9 \\
8 & 4 & & 9 \\
\hline
\end{tabular}

After five weeks in the program significant changes in student responses were captured. One of the main improvements was in the students' abilities to identify the physical aspects of the eye. For example, the percentage of students that could successfully identify the optic nerve increased by $15 \%$; retina responses increased 11\%; the percentage of students who could successfully describe the iris increased by $14 \%$; and students correctly identifying the function of the eyelid rose $25 \%$. The percentage of students correctly naming the distance between the cornea and the retina also rose by more than $300 \%$. The percentage of students who could correctly identify 'LASIK' surgery increased by $600 \%$, and the percentage of students who believed LASIK was a relatively safer surgical process rose by $9 \%$. As seen in Tables 1 and 2 , post assessment scores increased in both the science and engineering/technology topics, while scores were unchanged in mathematics.

\subsection{Data}

Table 3. Pre- and Post-Assessment Data for Science Topics.

\begin{tabular}{|llllllll|}
\hline $\begin{array}{c}\text { Assessment } \\
\text { Type }\end{array}$ & Min & Max & Mean & Std. Dev. & Variance & N \\
\hline Pre & 0 & 10 & 5.88 & 1.98 & 3.92 & 32 \\
Post & 2 & 11 & 7.54 & 1.74 & 3.02 & 26 \\
\hline
\end{tabular}

Table 4. Pre- and Post-Assessment Data for Engineering/Technology/Career Topics.

\begin{tabular}{|llllllll|}
\hline $\begin{array}{c}\text { Assessment } \\
\text { Type }\end{array}$ & Min & Max & Mean & Std. Dev. & Variance & N \\
\hline Pre & 0 & 5 & 2.78 & 1.11 & 1.23 & 32 \\
Post & 1 & 5 & 3.73 & 1.23 & 1.5 & 26 \\
& & & & & & & \\
\hline
\end{tabular}




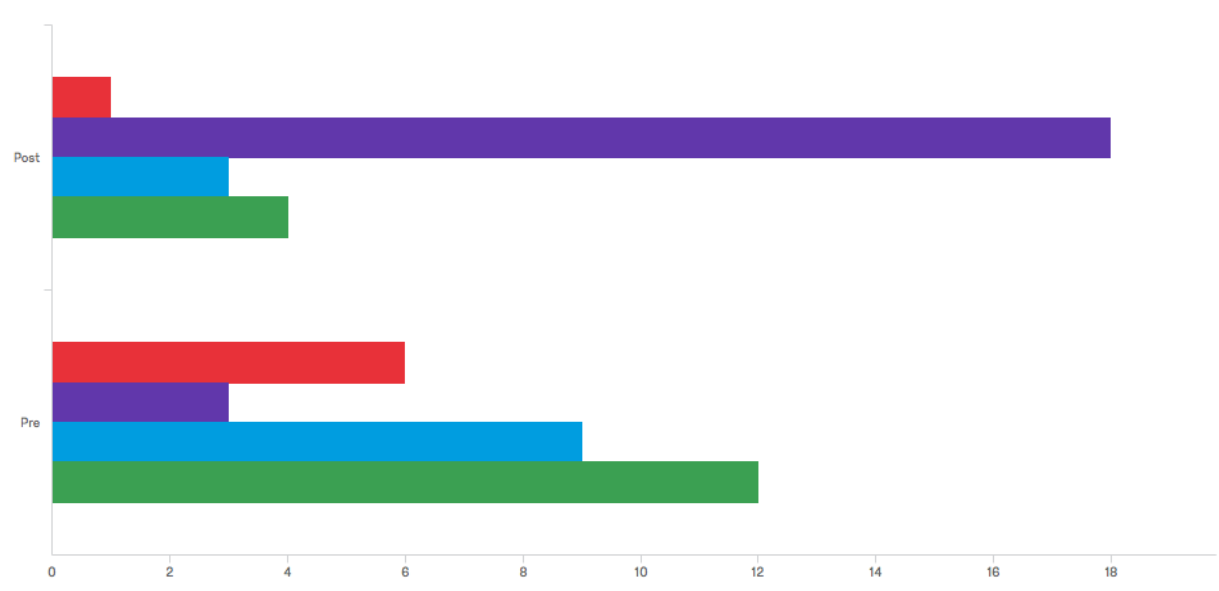

Figure 6. Graph of responses to pre- and post-assessment questions. Purple indicates a correct response.

Data from the S-STEM survey presented a surprising picture, as overall pre/post score evaluation showed a decrease in overall STEM attitudes among participants, though the results were not significant. These results are reported in the table below.

Table 5. Descriptive Statistics from S-STEM Survey of Participants

\begin{tabular}{|llllllll|}
\hline $\begin{array}{l}\text { S-STEM } \\
\text { Scale }\end{array}$ & Assessment Type & Min & Max & Mean & Std. Dev. & Variance & N \\
\hline Science & Pre & 1 & 5 & 3.78 & 0.74 & 5.4 & 23 \\
& Post & 1 & 5 & 3.66 & 0.89 & 7.9 & 25 \\
\hline Math & Pre & 1 & 5 & 3.82 & 0.55 & 3.02 & 23 \\
& Post & 1 & 5 & 3.79 & 0.52 & 2.69 & 25 \\
\hline Eng./Tech. & Pre & 2 & 5 & 3.25 & 0.43 & 1.81 & 23 \\
& Post & 1 & 5 & 3.16 & 0.7 & 4.95 & 25 \\
\hline & Pre & 1 & 5 & 4.1 & 0.56 & 3.1 & 23 \\
\hline 21st Cent. & & 1 & 5 & 4.06 & 0.71 & 4.9 & 25 \\
& Post & & & & & & \\
\end{tabular}




\section{CONCLUSIONS}

\subsection{Discussion}

Imhotep Academy's positive impact on student achievement provides validation for the model of the program. It also suggests that a continued focus on optics education is both fruitful and necessary to reach underserved students and demonstrate the value of optics careers. Additionally, the results from the S-STEM survey show that focused outreach efforts can also have an ancillary impact: it can reveal what careers students are uninterested in pursuing. Understanding why certain fields appeal to students while others do not is critical in keeping students on STEM pathways for the future career choices.

\subsection{Future Implications}

Outreach efforts should be extended to younger students since earlier impacts have been shown to have more impactful results on student persistence ${ }^{22}$. Teacher professional development could also extend the impact of optics education outreach to more students, particularly in rural areas where access to STEM professionals is more difficult. The impact on teacher perception of STEM should also be explored; anecdotal information suggests that teaching in Imhotep Academy has a positive influence but should be studied further.

\section{REFERENCES}

[1] Abel, J. R., Deitz, R. and Su, Y., "Are recent college graduates finding good jobs?" Current Issues in Economics and Finance 20(1) (2014).

[2] National Research Council, [Taking Science to School: Learning and Teaching Science in Grades K-8], National Academies Press (2007).

[3] Bybee, R. W., [The Case for STEM Education: Challenges and Opportunities], NSTA press (2013).

[4] Carnevale, A. P., Smith, N. and Strohl, J., [Help Wanted: Projections of Job and Education Requirements through 2018], Lumina Foundation (2010).

[5] Stein, J. D., Kapoor, K. G., Tootoo, J. L., Li, R., Wagner, A., Andrews, C. and Miranda, M. L., "Access to ophthalmologists in states where optometrists have expanded scope of practice " JAMA ophthalmology 136(1), 39-45 (2018).

[6] Atkinson, R. D. and Mayo, M. J., "Refueling the US innovation economy: Fresh approaches to science, technology, engineering and mathematics (STEM) education," The Information Technology \& Innovation Foundation, Forthcoming (2010).

[7] Hrabowski III, F. A., Maton, K. I. and Greif, G. L., [Beating the Odds: Raising Academically Successful African American Males], Oxford University Press (1998).

[8] Johnson, D. R., "Women of color in science, technology, engineering, and mathematics (STEM)," New Directions for Institutional Research 2011(152), 75-85 (2011).

[9] Maltese, A. V. and Tai, R. H., "Pipeline persistence: Examining the association of educational experiences with earned degrees in STEM among US students," Science education 95(5), 877-907 (2011).

[10] Falk, J. H. and Dierking, L. D., [The Museum Experience Revisited], Routledge (2016).

[11] Roberts, G. G., "SET for success: the supply of people with science, technology, engineering and mathematics skills: the report of Sir Gareth Roberts' review," (2002).

[12] Jones, J., "Closing the gender gap," Civil Engineering Magazine Archive 80(7), 60-63 (2010).

[13] Silim, A. and Crosse, C., "Women in Engineering," Women in Engineering (2014).

[14] Walker, J. M. G., Biggs, J., Gibbons, A., Putnam, G. G., Nally, T. and Shoop, B. L., "Optics education: a blueprint for the 21st century," Seventh International Conference on Education and Training in Optics and Photonics, 201-213 (2002).

[15] Soileau, M. and Pearson, J. E., "Is optics a separate discipline?" Fifth International Topical Meeting on Education and Training in Optics, 141-150 (1997).

[16] Andrews, C. L., Hunter, L., Moutawakkil, M. and Wilkins, L., "Center for Adaptive Optics Akamai Summer Internship Program," Age 9, 1 (2004).

[17] Johnson, A. M., Pompea, S. M., Arthurs, E. G., Walker, C. E. and Sparks, R. T., "Hands-on optics: an informal science education initiative," Novel Optical Systems Design and Optimization X, 66680D (2007).

[18] Pompea, S. M., Pfisterer, R. N., Ellis, S., Arion, D. N., Fienberg, R. T. and Smith, T. C., "Optical and system engineering in the development of a high-quality student telescope kit," Modeling, Systems Engineering, and Project Management for Astronomy IV, 773803 (2010). 
[19] Judy Donnelly, N. M., "Dumpster Optics: teaching and learning optics without a kit," 9946 (2016).

[20] Sahin, A., Gulacar, O. and Stuessy, C., "High school students' perceptions of the effects of international science Olympiad on their STEM career aspirations and twenty-first century skill development," Research in Science Education 45(6), 785-805 (2015).

[21] Unfried, A., Faber, M., Stanhope, D. S. and Wiebe, E., "The development and validation of a measure of student attitudes toward science, technology, engineering, and math (S-STEM)," Journal of Psychoeducational Assessment 33(7), 622-639 (2015).

[22] Alexander, A. B., "Exploration of Student Attitudes and Outcomes Toward STEM Careers After Repeated Participation in STEM Outreach," Unpublished dissertation, (2019).

[23] Russell, M. L., \& Atwater, M. M. (2005). "Traveling the road to success: A discourse on persistence throughout the science pipeline with African American students at a predominantly White institution," Journal of Research in Science Teaching, 42, 691-715 (2005).

[24] Miles, R. \& Matkins, J.J., "Science Enrichment for African American Students" Science Teacher v1(2), 36-41 (2004). [25] Smith. F.M. \& Hausafas, C.O., "Relationship of family support and ethnic minority students' achievement in science and mathematics," Science Education 82, 111-125, (1998).

[26] Hilliard-Clark, J. \& Gilchrist, P.O.., "Imhotep Academy Photonics Pre-College Program Model, (2010).

[27] Hilliard-Clark, J. \& Gilchrist, P.O.., "Photonics Xplorers and Leaders: Challenging Diverse Students in a Flat World for Emerging Careers" Optical Society of America, 1-10 (2007).

[28] Gilchrist, P. O., Hilliard-Clark, J. \& Bowles, T. "Optics Professional Development in North Carolina" SPIE Proceedings Optics Outreach and Education, 7783, 1-10 (2010).

[29] Gilchrist, P.O. "Science Teachers' Experiences Adopting Innovations in a Blended Learning Photonics Professional Development Program" Dissertation (2014).

[30] Sahin,A., Ayar, M., \& Adiguel, T. "STEM After-School Program Activities and Associated Outcomes on Student Learning" Educational Science: Theory and Practice, 14(1), 309-322, (2014).

[31] Lichtenstein, G, Chen, L., Smith, K. A. and Maldonado, T. A. "Retention and Persistence of Women and Minorities Along the Engineering Pathway in the United States", (2007). 